\title{
Synthesis and characterization of high ceramic yield polycarbosilane precursor for SiC
}

\author{
Mangesh LODHE ${ }^{a, *}$, Narendra BABU $^{a}$, A. $\operatorname{SELVAM}^{b}$, M. BALASUBRAMANIAN ${ }^{a}$ \\ ${ }^{a}$ Department of Metallurgical and Materials Engineering, Indian Institute of Technology Madras, Chennai 600036, India \\ ${ }^{b}$ FRP Institute, Chennai 600032, India
}

Received: June 10, 2015; Revised: July 22, 2015; Accepted: July 24, 2015

(C) The Author(s) 2015. This article is published with open access at Springerlink.com

\begin{abstract}
The polycarbosilane (PCS) precursor for SiC with high molecular weight and medium molecular weight distribution was synthesized from polydimethylsilane at normal pressure. The chemical formula, the number average molecular weight, and the polydispersivity index of the synthesized PCS are $\mathrm{SiC}_{1.94} \mathrm{H}_{5.01} \mathrm{O}_{0.028}, 1135$, and 1.66, respectively, which can be attributed to the higher reaction temperature used for polymerization. The polymer to ceramic conversion of PCS was completed at $900{ }^{\circ} \mathrm{C}$ with a ceramic yield of $85 \%$. The crystallization started at $1100{ }^{\circ} \mathrm{C}$, and at $1200{ }^{\circ} \mathrm{C}$, well resolved peaks of $\beta$-SiC were formed with small amount of $\alpha$-cristobalite. The X-ray diffraction (XRD) and transmission electron microscopy (TEM) studies indicated the presence of nanocrystalline $\beta$-SiC.
\end{abstract}

Keywords: synthesis; polycarbosilane (PCS); polymer-ceramic conversion; X-ray diffraction (XRD)

\section{Introduction}

Silicon carbide $(\mathrm{SiC})$ is one of the most leading candidate materials for various structural and functional applications, as it possesses very good thermo-mechanical properties [1]. The polymer derived ceramic route gives the tailored chemical composition and nanostructure material by proper thermal treatment under a controlled inert atmosphere [2]. The preceramic polymer and its molecular structure influence the chemical composition, the phase distribution, and the entire microstructure of the converted ceramics. Therefore, the chemical and physical properties of polymer derived ceramics can be changed to a major extent by tailoring the polymer

* Corresponding author.

E-mail: mmlodhe@gmail.com precursor [3]. Hence, the synthesis of preceramic polymers is one of the important stages in the area of polymer derived ceramics and its composites. Polycarbosilane (PCS), the precursor for SiC, has been synthesized by thermal decomposition of polydimethylsilane under high pressure in an autoclave [4]. The autoclave method is technically difficult and expensive. Yajima and his co-workers [5] have tried to synthesize polycarbosilane without using autoclave, but it has low molecular weight and low ceramic yield. The higher reaction temperature and/or longer reaction time tend to give the polycarbosilane of higher molecular weight and broader distribution [6]. In the present study, an attempt has been made to synthesize the high molecular weight and high ceramic yield polycarbosilane from polydimethylsilane without using autoclave. The synthesized polycarbosilane was completely characterized and the ceramic yield was determined. 


\section{Experimental details}

\section{1 Synthesis of polydimethylsilane}

Polydimethylsilane was synthesized by the reaction of dimethyldichlorosilane with sodium in xylene at $120{ }^{\circ} \mathrm{C}$ as reported elsewhere [7]. Metallic sodium was chopped into $5 \mathrm{~mm} \times 5 \mathrm{~mm}$ pieces and introduced into reaction flask containing xylene. The liquid surface was covered with nitrogen gas to create an inert atmosphere. Dimethyldichlorosilane was poured on a dropping funnel. To start the reaction, the flask containing sodium pieces and xylene was heated to $120^{\circ} \mathrm{C}$. The metallic sodium thus melted at $98{ }^{\circ} \mathrm{C}$ and stayed at the bottom of the flask. Dimethyldichlorosilane was added drop wise into the flask with continuous stirring to allow dechlorination to take place. After the addition of dimethyldichlorosilane, the reaction mixture was refluxed at $120{ }^{\circ} \mathrm{C}$ for $8 \mathrm{~h}$. After complete reaction, xylene (solvent) was removed from the product by suction filtration followed by natural drying, and the resulting product was a bluish-purple precipitate. The un-reacted sodium from the precipitate was then removed by treating with methanol. The $\mathrm{NaCl}$ and low molecular weight polydimethylsilane were removed by washing with deionized water and acetone. The final white precipitate was dried in oven at $120^{\circ} \mathrm{C}$ for $1 \mathrm{~h}$.

\section{2 Synthesis of polycarbosilane}

The polydimethylsilane powder was placed in a two-necked round-bottom borosilicate flask attached with a reflux condenser and an inlet of nitrogen gas. After purging nitrogen gas, the polydimethylsilane powder was heated in electric furnace to carry out the reflux reaction. The polydimethylsilane was heated at various temperatures starting from 320 to $370{ }^{\circ} \mathrm{C}$. At $350{ }^{\circ} \mathrm{C}$, the color of polydimethylsilane turned to creamy white. The polydimethylsilane melted and converted into liquid state in the temperature range of 360-370 ${ }^{\circ} \mathrm{C}$. Thereafter, the liquid was refluxed for $5 \mathrm{~h}$ and then heated up to $450{ }^{\circ} \mathrm{C}$ to remove volatile components. It was allowed to cool at room temperature and highly viscous product was taken out from the flask by adding n-hexane. The solution was stirred and then filtered to get yellowish-brown viscous liquid. The left over traces of n-hexane were removed by a rotary evaporator and subsequently heated in the tubular furnace in the presence of argon gas to $250{ }^{\circ} \mathrm{C}$ for $30 \mathrm{~min}$ to remove the low molecular weight components. The substance thus obtained was yellowish-shiny crystals. Thus the thermal decomposition of polydimethylsilane yielded polycarbosilane, which is the polymer precursor for silicon carbide.

\section{3 Characterization}

Fourier transform infrared spectroscopy (FT-IR) analysis for polydimethylsilane and polycarbosilane was carried out using Perkin Elmer 2000 Spectrum One spectrometer, to confirm the functional groups. $\mathrm{KBr}$ pellets were used for the analysis, which were prepared by compressing a finely ground mixture of about $2 \mathrm{mg}$ of sample and $100 \mathrm{mg}$ of $\mathrm{KBr}$ powder.

The determination of average molecular weight $\left(M_{\mathrm{w}}\right)$, number average molecular weight $\left(M_{\mathrm{n}}\right)$, and mass distribution (polydispersivity index) of the polydimethylsilane and polycarbosilane was carried out by gel permeation chromatography (GPC) technique using Waters 2414 refractive index detector. Tetrahydrofuran (THF) was used as eluant at a flow rate of $1.0 \mathrm{~mL} / \mathrm{min}$ using Waters M45 pump at room temperature.

Thermal decomposition of the polycarbosilane up to $900{ }^{\circ} \mathrm{C}$ in nitrogen gas was investigated by simultaneous thermal gravimetric (TG) and differential thermal analysis (DTA) techniques carried out with a high temperature NETZSCH STA $409 \mathrm{PC} / \mathrm{PG}$ at a heating rate of $10{ }^{\circ} \mathrm{C} / \mathrm{min}$ under nitrogen gas flow rate of $20 \mathrm{~cm}^{3} / \mathrm{min}$.

Carbon and hydrogen contents of the polycarbosilane were analyzed by using Perkin-Elmer 2400 Series CHN analyzer. Silicon content was determined by inductive coupled plasma-optical emission spectroscopy (ICP-OES, Perkin Elmer Optima $5300 \mathrm{DV})$. The oxygen content was obtained by the difference.

X-ray diffraction (XRD) analysis was carried out for polycarbosilane pyrolysed at 900, 1000, 1100, and $1200{ }^{\circ} \mathrm{C}$ for $1 \mathrm{~h}$ in $\mathrm{Ar}$ atmosphere with a PANalytical diffractometer using $\mathrm{Cu} \mathrm{K} \alpha$ radiation. Line broadening of (111) peak of $\mathrm{SiC}$ was used for crystallite size determination by using Scherrer formula. Morphological characteristics were obtained by transmission electron microscopy (TEM, Philips CM12).

\section{Results and discussion}

The FT-IR spectrum of polydimethylsilane is shown in 
Fig. 1. The major groups present are $\mathrm{Si}-\mathrm{CH}_{3}(1245$, $835,745,690$, and $\left.625 \mathrm{~cm}^{-1}\right), \mathrm{C}-\mathrm{H}(2950,2900$, and $\left.1400 \mathrm{~cm}^{-1}\right), \mathrm{Si}-\mathrm{O}\left(1030 \mathrm{~cm}^{-1}\right)$, and $\mathrm{O}-\mathrm{H}$ (3430 and $1630 \mathrm{~cm}^{-1}$ ) [7,8]. The presence of $\mathrm{Si}-\mathrm{CH}_{3}$ functional group confirms the formation of polydimethylsilane. The presence of $\mathrm{Si}-\mathrm{CH}_{3}$ group indicates that polycarbosilane with $\mathrm{Si}-\mathrm{C}$ backbone could be obtained by thermal decomposition of polydimethylsilane. The molar mass distribution was measured by GPC. The average molecular weight $\left(M_{\mathrm{w}}\right)$, the number average molecular weight $\left(M_{\mathrm{n}}\right)$, and the complete molecular weight distribution (polydispersivity index) of polydimethylsilane are found to be 1900, 1300, and 1.51 , respectively.

The FT-IR spectrum of polycarbosilane is also shown in Fig. 1. Polycarbosilane which is synthesized by the thermal decomposition of polydimethylsilane at elevated temperature consists of $\mathrm{Si}-\mathrm{CH}_{2}-\mathrm{Si}$ group and also other functional groups of polycarbosilane. The silicon free radical is formed by the cleavage of $\mathrm{Si}-\mathrm{Si}$ bond during the application of heat and the rearrangement is done by the insertion of methyl group in the chain, which gives rise to $\mathrm{Si}-\mathrm{CH}_{2}-\mathrm{Si}$ and $\mathrm{Si}-\mathrm{H}$ groups [4]. A band observed at $1025 \mathrm{~cm}^{-1}$ is very

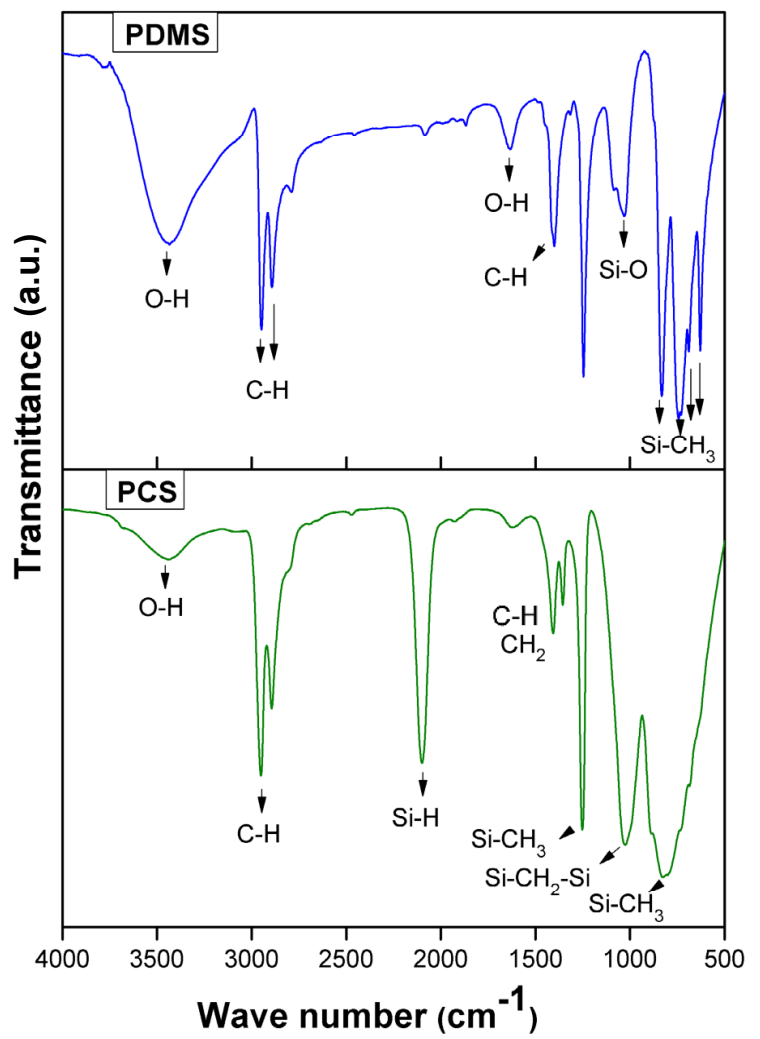

Fig. 1 FT-IR spectra of polydimethylsilane (PDMS) and polycarbosilane (PCS). strong, which corresponds to $\mathrm{CH}_{2}$ bending in the $\mathrm{Si}-\mathrm{CH}_{2}-\mathrm{Si}$ group. The bands attributed to $\mathrm{Si}-\mathrm{CH}_{3}$ are $\mathrm{Si}-\mathrm{CH}_{3}$ stretching at $1250 \mathrm{~cm}^{-1}$ and $\mathrm{C}-\mathrm{H}$ stretching at $2950 \mathrm{~cm}^{-1}$. The band at $1400 \mathrm{~cm}^{-1}$ corresponds to $\mathrm{C}-\mathrm{H}$ stretching in $\mathrm{Si}-\mathrm{CH}_{3}$ and $1360 \mathrm{~cm}^{-1}$ corresponds to $\mathrm{CH}_{2}$ stretching in $\mathrm{Si}-\mathrm{CH}_{2}-\mathrm{Si}$. The strong band of $\mathrm{Si}-\mathrm{H}$ is at $2100 \mathrm{~cm}^{-1}$ and the $\mathrm{O}-\mathrm{H}$ stretching in $\mathrm{H}_{2} \mathrm{O}$ is at 3430 and $1630 \mathrm{~cm}^{-1}$. FT-IR data of synthesized polycarbosilane are in well agreement with those reported in the literature $[9,10]$.

The chemical composition of polycarbosilane precursor is $\mathrm{Si} 46 \mathrm{wt} \%$, C $38.18 \mathrm{wt} \%, \mathrm{H} 8.19 \mathrm{wt} \%$, N $0.13 \mathrm{wt} \%$, and $\mathrm{O} 7.5 \mathrm{wt} \%$. The empirical formula of synthesized polycarbosilane is $\mathrm{SiC}_{1.94} \mathrm{H}_{5.01} \mathrm{O}_{0.028}$. The elemental analysis result shows that the atomic ratio of carbon to silicon in the polycarbosilane precursor is about 2:1. The softening point of the obtained polycarbosilane is found to be in the range of 240 $250{ }^{\circ} \mathrm{C}$. The GPC curve for polycarbosilane is shown in Fig. 2 . The average molecular weight $\left(M_{\mathrm{w}}\right)$ and number average molecular weight $\left(M_{\mathrm{n}}\right)$ of polycarbosilane are found to be 1888 and 1135 , respectively. The polydispersity index $\left(M_{\mathrm{w}} / M_{\mathrm{n}}\right)$ of polycarbosilane is therefore about 1.66. The GPC curve shows the medium molecular weight distribution, and it can be correlated to the evolution of lower molecular weight PCS during its synthesis at normal pressure. Softening point can be the macroscopic indication of molecular weight, i.e., the more the softening point, the higher the molecular weight.

The polycarbosilane was obtained by thermal decomposition of polydimethylsilane at higher temperature. As the reaction temperature was higher, more $\mathrm{Si}-\mathrm{Si}$ bonds were dissociated, and more

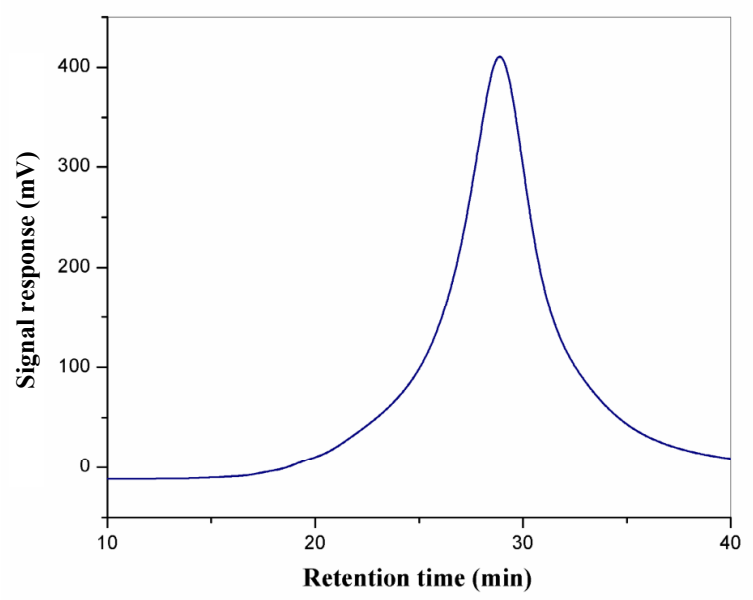

Fig. 2 GPC curve for polycarbosilane. 
$\mathrm{Si}-\mathrm{CH}_{2}-\mathrm{Si}$ groups which are the backbone of polycarbosilane molecule form through the Kumada rearrangement [6]. Hence the final product of polycarbosilane will consist of longer molecular chains which at the end give rise to higher molecular weight and medium molecular weight distribution.

Thermal behavior of polycarbosilane was studied by using TGA-DTA. The TGA-DTA curves of polycarbosilane are shown in Fig. 3. In the first stage, the TG curve gradually drops from 100 to $370{ }^{\circ} \mathrm{C}$, which is relatively small with no significant weight loss in this temperature range. This weight loss is due to the evaporation of reaction product $\mathrm{H}_{2}$ and some low molecular weight polycarbosilane [11]. In the second stage, the TG curve falls off rapidly from 370 to $550{ }^{\circ} \mathrm{C}$ which is substantiated by a large exothermic peak in the DTA curve. The weight loss in this region is $5 \mathrm{wt} \%$, and it could be due to evaporation of gaseous product such as $\mathrm{CH}_{4}$ and $\mathrm{H}_{2}$ because of dehydrogenation and dehydrocarbonation condensation of polycarbosilane molecule [12]. In the third stage, TG continues to fall from 550 to $800{ }^{\circ} \mathrm{C}$ and the corresponding weight loss is $8.8 \mathrm{wt} \%$. The weight loss could be due to the decomposition of organic side groups such as $\mathrm{Si}-\mathrm{H}$, $\mathrm{Si}-\mathrm{CH}_{3}$, and $\mathrm{C}-\mathrm{H}$ in $\mathrm{Si}-\mathrm{CH}_{2}-\mathrm{Si}$ [13]. After $800{ }^{\circ} \mathrm{C}$, there is hardly any weight loss and the exothermic peak at $900{ }^{\circ} \mathrm{C}$ shows the crystallization of amorphous phase. The polymer to ceramic conversion is completed at $900{ }^{\circ} \mathrm{C}$. At $900{ }^{\circ} \mathrm{C}$, the ceramic yield is $85 \mathrm{wt} \%$. Such high yield is resulted due to increased cross-linked structure of polycarbosilane precursor with high molecular weight. The high molecular weight leads to low weight loss during the cross-linking and pyrolysis and thereby increases the ceramic yield.

Polycarbosilane precursor was pyrolyzed at different temperatures starting from 900 to $1200{ }^{\circ} \mathrm{C}$ in argon

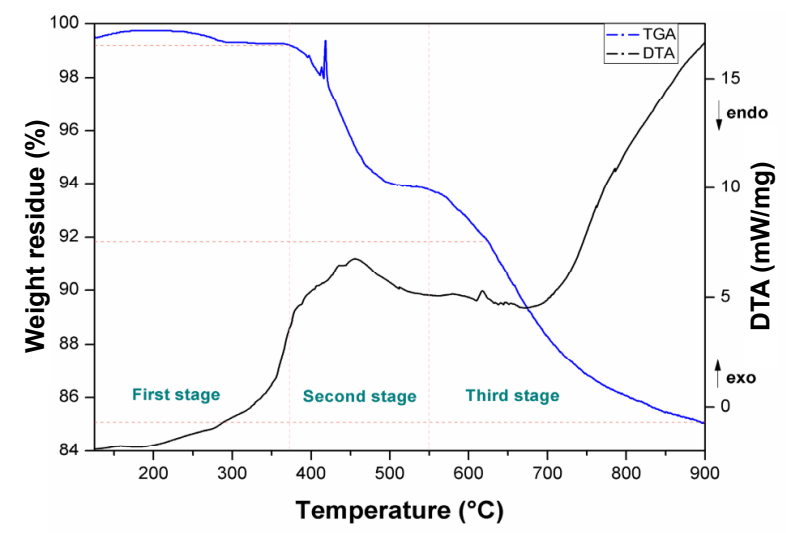

Fig. 3 TGA-DTA of polycarbosilane in $\mathrm{N}_{2}$ atmosphere. atmosphere to study the formation $\beta$-SiC phase. XRD patterns of samples pyrolysed at different temperatures are shown in Fig. 4. From TG curve, it is inferred that the polymer to ceramic conversion has completed at $900{ }^{\circ} \mathrm{C}$ and hence polycarbosilane pyrolysed at 900 and $1000{ }^{\circ} \mathrm{C}$ is resulted in amorphous structure and highly disordered in nature. However, polycarbosilane pyrolyzed at $1100{ }^{\circ} \mathrm{C}$ has resulted in a broad peak which appears at $36.02^{\circ}$. Although the crystallization is incomplete, it indicates the presence of high local ordering of tetrahedral $\mathrm{SiC}$. After the pyrolysis at $1200{ }^{\circ} \mathrm{C}$, the residue gives a more defined XRD pattern. The pattern shows the major peaks at $2 \theta=36.02^{\circ}$, $60.84^{\circ}$, and $71.83^{\circ}$ corresponding to the (111), (220), and (311) diffraction planes of face centered cubic (FCC) $\beta$-SiC polymorph of silicon carbide. The crystallite size of $\mathrm{SiC}$ is found to be $6 \mathrm{~nm}$. In addition to this, a sharp peak appears at $2 \theta=22.37^{\circ}$ resembling the (101) diffraction plane of $\alpha$-cristobalite. At $1100{ }^{\circ} \mathrm{C}$, the broader $\beta$-SiC peaks and a broad $\alpha$-cristobalite peak at $2 \theta=22.37^{\circ}$ are observed. The same peaks also appear in polycarbosilane pyrolyzed at $1200{ }^{\circ} \mathrm{C}$ with a sharp $\alpha$-cristobalite peak. This infers that the amorphous $\alpha$-cristobalite phase is transformed to crystalline $\alpha$-cristobalite phase at $1200{ }^{\circ} \mathrm{C}$. Above $1100{ }^{\circ} \mathrm{C}$, the diffraction peaks of $\beta$-SiC are observed

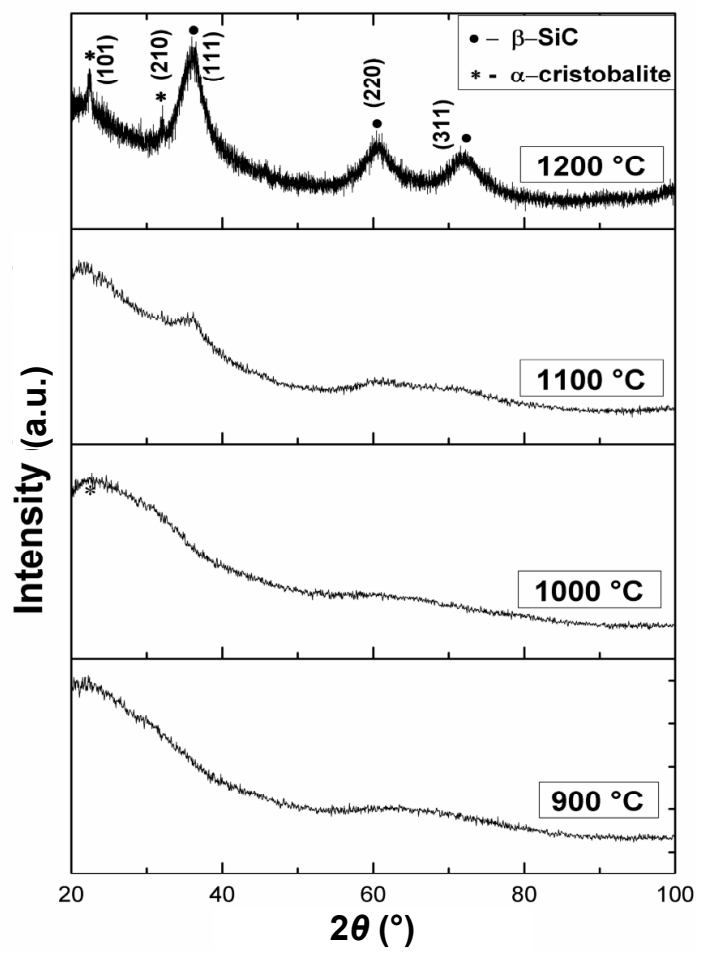

Fig. 4 XRD patterns of PCS pyrolysed between 900 and $1200^{\circ} \mathrm{C}$ 
and the diffraction peaks become sharper as pyrolysis temperature increases from 1100 to $1200{ }^{\circ} \mathrm{C}$, suggesting a progressive crystallization process.

The bright and dark filed TEM micrographs (Figs. 5(a) and 5(b)) of PCS pyrolyzed at $1200{ }^{\circ} \mathrm{C}$ show the nanocrystalline nature of $\mathrm{SiC}$. The crystallite size of $\mathrm{SiC}$ ranges from 5 to $12 \mathrm{~nm}$. The average crystallite size observed in TEM is larger than the calculated from XRD broadening of (111) plane. This difference could be due to the complicated shape of diffraction peak by the presence of high intensity background. The selected area electron diffraction (SAED) pattern (Fig. 5(c)) shows the strong sharp rings, which indicate the crystalline nature of $\mathrm{SiC}$. This electron diffraction pattern can be indexed as (200), (220), and (311) crystallographic planes of $\beta$-SiC.

\section{Conclusions}

The polycarbosilane of higher molecular weight and medium molecular weight distribution has been synthesized without using autoclave. The chemical formula of polycarbosilane is $\mathrm{SiC}_{1.94} \mathrm{H}_{5.01} \mathrm{O}_{0.028}$. The polymer to ceramic conversion yield is $85 \mathrm{wt} \%$.

After pyrolysis, the FCC $\beta$-SiC has been obtained with crystallite size of $6 \mathrm{~nm}$. This study demonstrates that final structure of pyrolyzed ceramic can be tailored by modifying the polymeric precursor structure.

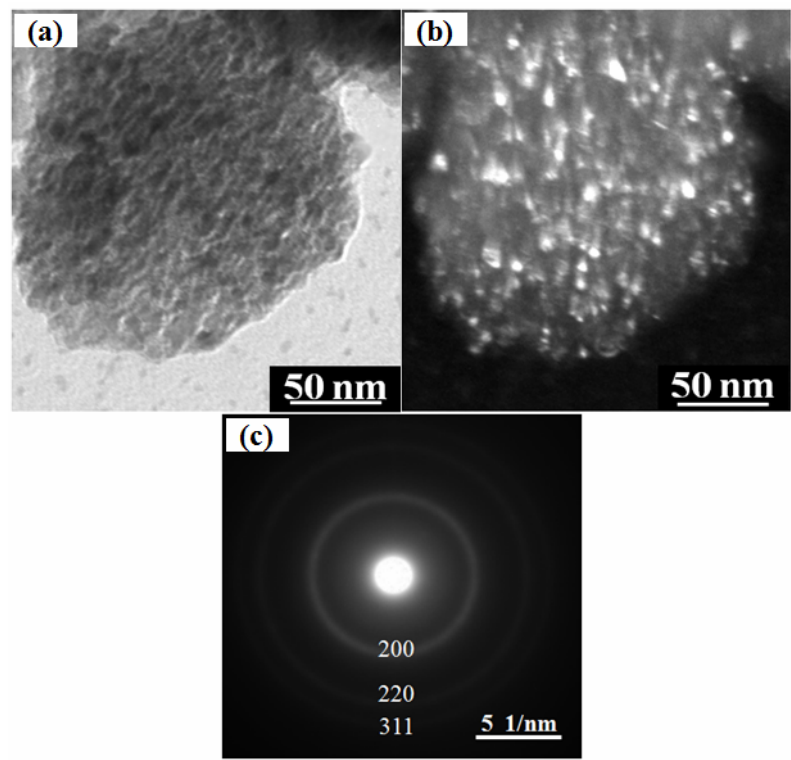

Fig. 5 (a) Bright field and (b) dark field TEM images and (c) SAED pattern of PCS pyrolyzed at $1200{ }^{\circ} \mathrm{C}$.

\section{Acknowledgements}

We are grateful to Mr. Shrikant for his help in carrying out the experiments. We further acknowledge to Mr. Niraj for valuable technical help in manuscript preparation.

Open Access: This article is distributed under the terms of the Creative Commons Attribution License which permits any use, distribution, and reproduction in any medium, provided the original author(s) and the source are credited.

\section{References}

[1] Herzog A, Thünemann M, Vogt U, et al. Novel application of ceramic precursors for the fabrication of composites. J Eur Ceram Soc 2005, 25: 187-192.

[2] Miele P, Bernard S, Cornu D, et al. Recent developments in polymer-derived ceramic fibers (PDCFs): Preparation, properties and applications-A review. Soft Mater 2007, 4: 249-286.

[3] Miller RD, Michl J. Polysilane high polymers. Chem Rev 1989, 89: 1359-1410.

[4] Birot M, Pillot J-P, Dunogues J. Comprehensive chemistry of polycarbosilanes, polysilazanes, and polycarbosilazanes as precursors of ceramics. Chem Rev 1995, 95: 1443-1477.

[5] Yajima S, Omori M, Hayashi J, et al. Simple synthesis of continuous $\mathrm{SiC}$ fiber with high tensile strength. Chem Lett 1976, 5: 551-554.

[6] Chen J, He G, Liao Z, et al. Control of structure formation of polycarbosilane synthesized from polydimethylsilane by Kumada rearrangement. J Appl Polym Sci 2008, 108: 3114-3121.

[7] Yajima S, Hasegawa Y, Hayashi J, et al. Synthesis of continuous silicon carbide fibre with high tensile strength and high Young's modulus. J Mater Sci 1978, 13: 2569-2576.

[8] Cheng X, Xie Z, Song Y, et al. Structure and properties of polycarbosilane synthesized from polydimethylsilane under high pressure. J Appl Polym Sci 2006, 99: 1188-1194.

[9] Ly HQ, Taylor R, Day R, et al. Conversion of polycarbosilane (PCS) to SiC-based ceramic. Part 1. Characterisation of PCS and curing products. J Mater Sci 2001, 36: 4037-4043.

[10] Cheng X, Xie Z, Xiao J, et al. Influence of temperature on the properties of polycarbosilane. J Inorg Organomet Polym Mater 2005, 15: 253-259.

[11] Yive NSCK, Corriu RJP, Leclercq D, et al. Silicon carbonitride from polymeric precursors: Thermal cross-linking and pyrolysis of oligosilazane model compounds. Chem Mater 1992, 4: 141-146.

[12] Li H, Zhang L, Cheng L, et al. Polymer-ceramic conversion of a highly branched liquid polycarbosilane for SiC-based ceramics. J Mater Sci 2008, 43: 2806-2811.

[13] Hasegawa Y, Iimura M, Yajima S. Synthesis of continuous silicon carbide fibre. J Mater Sci 1980, 15: 720-728. 